\title{
ARTICLE OPEN Skillful empirical subseasonal prediction of landfalling atmospheric river activity using the Madden-Julian oscillation and quasi-biennial oscillation
}

\author{
Bryan D. Mundhenk (D) ${ }^{1}$, Elizabeth A. Barnes ${ }^{1}$, Eric D. Maloney ${ }^{1}$ and Cory F. Baggett $\mathbb{D}^{1}$
}

\begin{abstract}
Upon landfall, atmospheric rivers (ARs) — plumes of intense water vapor transport-often trigger weather and hydrologic extremes. Presently, no guidance is available to alert decision makers to anomalous AR activity within the subseasonal time scale ( 2-5 weeks). Here, we construct and evaluate an empirical prediction scheme for anomalous AR activity based solely on the initial state of two prominent modes of tropical variability: the Madden-Julian oscillation (MJO) and the quasi-biennial oscillation (QBO). The MJO-the dominant mode of intraseasonal variability in the tropical troposphere-modulates landfalling AR activity along the west coast of North America by exciting large-scale circulation anomalies over the North Pacific. In light of emerging science regarding the modulation of the MJO by the QBO-the dominant mode of interannual variability in the tropical stratosphere-we demonstrate that the MJO-AR relationship is further influenced by the QBO. Evaluating the prediction scheme over 36 boreal winter seasons, we find skillful subseasonal "forecasts of opportunity" when knowledge of the MJO and the QBO can be leveraged to predict periods of increased or decreased AR activity. Certain MJO and QBO phase combinations provide empirical subseasonal predictive skill for anomalous AR activity that exceeds that of a state-of-the-art numerical weather prediction model. Given the wide-ranging impacts associated with landfalling ARs, even modest gains in the subseasonal prediction of anomalous AR activity may support decision making and benefit numerous sectors of society.
\end{abstract}

npj Climate and Atmospheric Science (2018)1:20177; doi:10.1038/s41612-017-0008-2

\section{INTRODUCTION}

A comparative gap in forecast guidance exists between mediumrange weather forecasts (up to 2 weeks) and seasonal outlooks $\left(3+\right.$ months). ${ }^{1-3}$ Thus, opportunities abound to add far-reaching value to society with skillful predictions of extreme, and frequently hazardous, weather events that occur within this so-called subseasonal-to-seasonal gap. ${ }^{3}$ Sectors such as agriculture, energy production, resource management, and insurance stand to benefit from advance notice of weather extremes in order to prepare for such events.

Here, we focus on the subseasonal time scale that spans forecast lead times of $\sim 2-5$ weeks. Skillful predictions of extratropical phenomena within this time scale generally rely on the prediction of large-scale circulation anomalies, ${ }^{4}$ which are often linked to tropical disturbances that excite quasi-stationary Rossby waves that propagate into the extratropics. ${ }^{5-7}$ Indeed, predictive power in the subseasonal time scale is largely associated with the evolution of far-reaching teleconnections produced by tropical phenomena such as the Madden-Julian oscillation (MJO). ${ }^{8,9}$ The MJO is the dominant mode of intraseasonal variability in the tropical troposphere and is often characterized by a large-scale pattern of coupled anomalous atmospheric circulation and deep convection that propagates eastward along the equator with a period of $\sim 30-90$ days. ${ }^{10}$ Additionally, the MJO is known to be an important source of subseasonal predictability $9,11,12$ and can support predictions of various phenomena outside of the tropics. For example, a recently developed empirical model for predicting North American 2-m temperatures based on the MJO, the El Niño-Southern Oscillation (ENSO) cycle, and linear trends produces skill and provides valuable guidance beyond a basic climatological forecast. ${ }^{13}$ Moreover, the teleconnection patterns associated with the ENSO cycle and the MJO provide a scientific basis for subseasonal prediction with operational forecast models. ${ }^{14}$

Emerging science is illuminating the influence that the state of the tropical stratosphere has on the MJO and its teleconnections. Here, the state of the stratosphere is represented by the phase of the quasi-biennial oscillation (QBO). The $\mathrm{QBO}$ is the dominant mode of the variability in the tropical stratosphere and is itself highly predictable. ${ }^{15}$ The QBO represents a downward propagating shift in the mean zonal winds in the equatorial stratosphere from westerlies to easterlies and back again, with a period of $\sim 2$ years. ${ }^{16}$ A growing body of research suggests that the state of the stratosphere, as represented by the QBO, influences the nature and predictability of the MJO, ${ }^{17,18}$ as well as the MJO's associated atmospheric teleconnections. ${ }^{18,19}$ For example, MJO activity during boreal winter is generally higher in amplitude and slower to propagate during the easterly phase of the QBO than during the westerly phase. ${ }^{17,19-21}$ This modulation of the MJO by the QBO can occur independent of the ENSO cycle. ${ }^{17,19,21}$ While the physical processes responsible for the modulation of the MJO by the QBO are still being investigated, the relationship appears to be dominated by the regulation of the near-tropopause

${ }^{1}$ Department of Atmospheric Science, Colorado State University, Fort Collins, CO, USA

Correspondence: Bryan D. Mundhenk (bryan.mundhenk@colostate.edu)

Received: 12 May 2017 Revised: 3 July 2017 Accepted: 3 August 2017

Published online: 01 February 2018 
a)

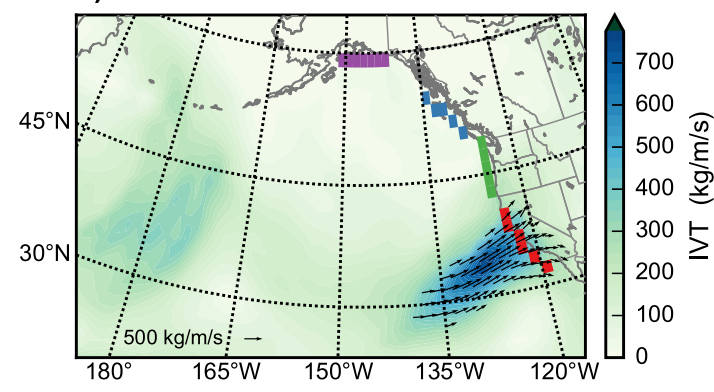

b)

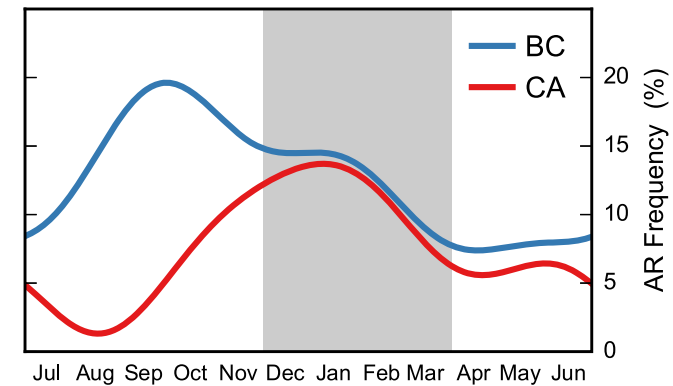

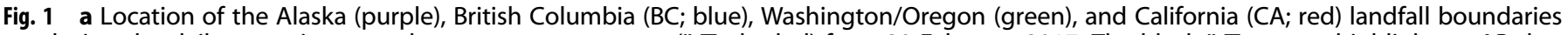

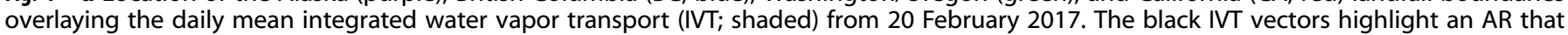

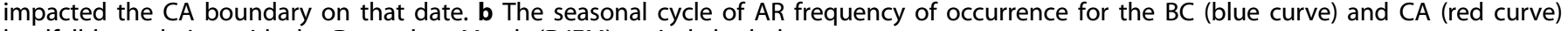
landfall boundaries, with the December-March (DJFM) period shaded

temperature and static stability and hence a modulation of organized deep convection. ${ }^{17,21}$

In this work, we construct and evaluate an empirical prediction scheme targeting anomalous landfalling atmospheric river (AR) activity along the west coast of North America. ARs are plumes of intense tropospheric water vapor transport that often result in weather and/or hydrologic extremes (e.g., heavy rainfall, flash floods) upon landfall. ${ }^{22-25}$ Repeated landfalling ARs or a complete lack thereof may result in periods of precipitation abundance or drought for regions along the west coast of North America. ${ }^{26,27}$ Several studies suggest the potential for skillful subseasonal prediction based on observed relationships between the MJO and AR activity. ${ }^{28-32}$ Here, we show that knowledge of the state of the $\mathrm{MJO}$ and the QBO can provide skillful predictions of anomalous AR activity up to 5 weeks in advance during boreal winter months. Because of the wide-ranging impacts associated with landfalling ARs, myriad sectors of society may benefit from skillful predictions of anomalous AR activity along the west coast of North America.

\section{RESULTS}

Atmospheric rivers (ARs) impact the west coast of North America during every month of the year. ${ }^{32}$ However, regions along the coast experience a pronounced seasonality in AR frequency of occurrence that generally varies with latitude. ${ }^{33,34}$ The landfall boundaries used in this study, as identified in Fig. 1a, are no exception. Figure $1 \mathrm{~b}$ shows the seasonal cycle of landfalling ARs near British Columbia (BC; blue) and California (CA; red) based on ARs identified in the second modern-era retrospective analysis for research and applications (MERRA-2) data set $^{35}$ (results for the Alaska and Washington/Oregon landfall boundaries are provided in the Supplementary Information). We focus our analysis on the December through March (DJFM) period, as shaded in Fig. 1b, when ARs frequently occur near both the British Columbia and California landfall boundaries, when teleconnection patterns are expected to be the most robust over the North Pacific, and when the aforementioned MJO-QBO link has been observed. In Fig. 1b, ARs occur at frequencies of $\sim 12.4 \%$ and $11.5 \%$ of all days during DJFM for the British Columbia and California boundaries, respectively. Not shown is the substantial year-to-year variability in AR occurrences ${ }^{32,34}$ indicating that landfalling ARs are also influenced by longer time scale modes of variability such as the ENSO cycle.

AR activity near these landfall boundaries not only varies on seasonal and longer time scales, but also within the subseasonal time scale. Here, we assess the modulation of AR activity following periods when the MJO is active. The MJO is parsed into eight phases that relate to the approximate location of the anomalous convection associated with the MJO, according to the components of the real-time multivariate MJO (RMM) index ${ }^{36}$ (Methods).

\section{a) British Columbia}
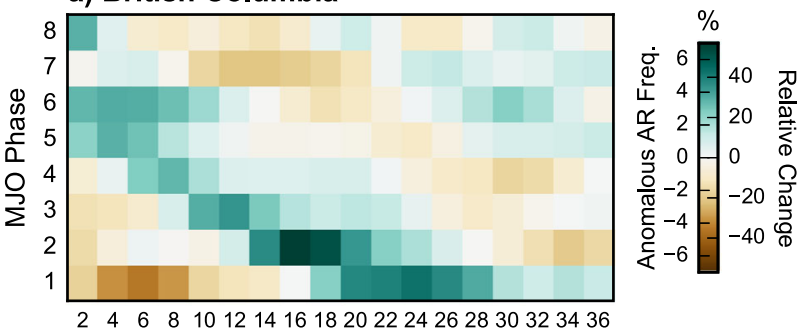

b) California

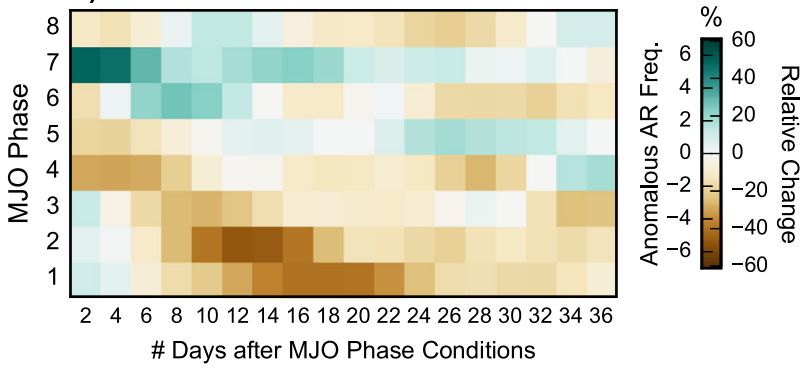

Fig. 2 Composite anomalous AR activity as a function of MJO phase ( $y$ axis) and number of days after active MJO phase conditions ( $x$ axis) in terms of anomalous frequency of occurrence (\%, left range of colorbar) and the change relative to the location's mean DJFM AR frequency (\% change, right range of colorbar) for the (a) British Columbia and (b) California landfall boundaries

Figure 2 depicts anomalous AR frequency of occurrence following dates when the MJO is active in a given phase, based on the 36 DJFM seasons (1980-2016) within the MERRA-2 record. These composite anomalies may also be thought of in terms of percent change relative to the aforementioned $12.4 \%$ and $11.5 \%$ DJFM mean AR frequencies for British Columbia and California, respectively. As such, Fig. 2 reveals composite patterns of anomalous AR activity following certain MJO phases that approach, or even exceed, $\pm 50 \%$ of the seasonal AR frequency of occurrence. The opposing anomaly patterns in Fig. 2 also capture a tradeoff in AR activity between British Columbia and California. For example, the increase in AR activity near British Columbia $\sim 2$ weeks following MJO phase 2 contrasts with a simultaneous decrease in activity near California (see also ref. ${ }^{34}$ ).

In addition to the modulation of AR activity following active MJO periods, Fig. 2 captures some key characteristics of the MJO and its extratropical response. For example, the angled, alternating pattern of anomalous AR activity captures the eastward propagation of the canonical MJO signal. Additionally, Fig. 2 reveals that the maximum MJO-related impacts may take several 
a) British Columbia, QBO Independent

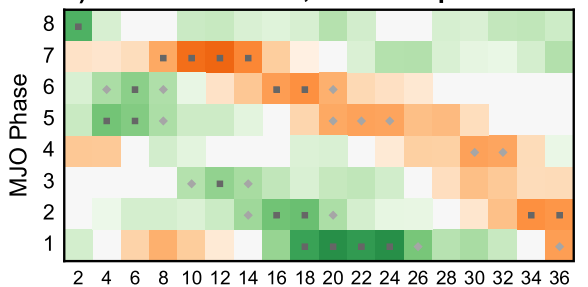

c) British Columbia, EQBO

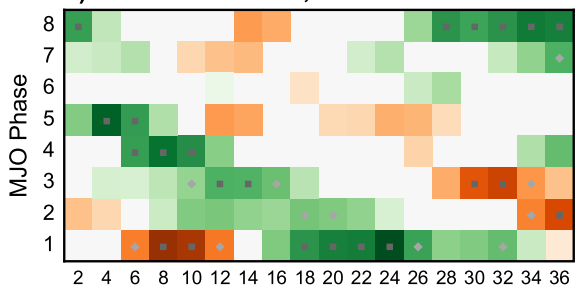

e) British Columbia, WQBO

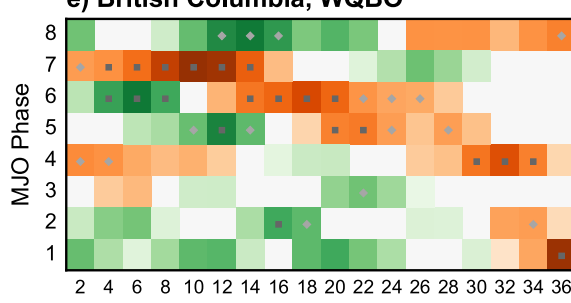

Forecast Lead (\# days) b) California, QBO Independent

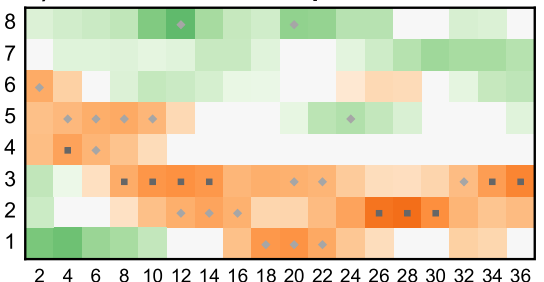

d) California, EQBO

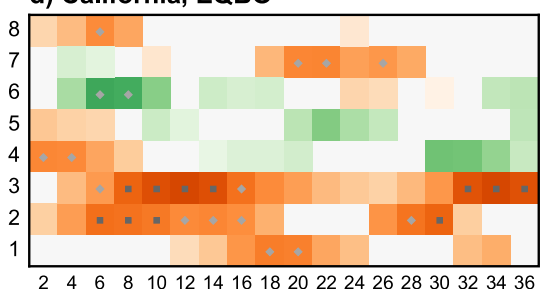

f) California, WQBO

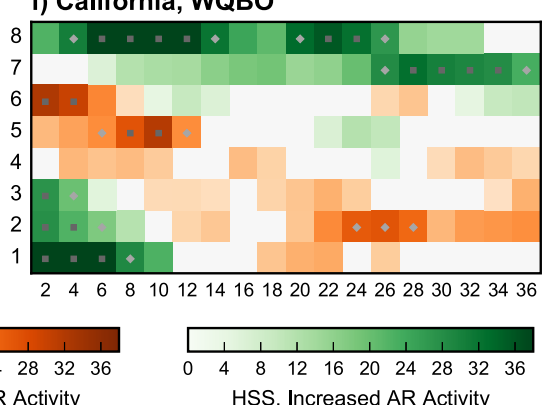

Fig. 3 Heidke skill score (HSS) values as a function of MJO phase ( $y$ axis) and forecast lead time ( $x$ axis) for the British Columbia (left column) and California (right column) landfall boundaries, $(\mathbf{a}, \mathbf{b})$ independent of the state of the QBO, as well as conditioned on (c, d) EQBO and (e, $\mathbf{f})$ WQBO. Only conditional combinations where the HSS is positive are shaded. The shading is based on the dominant AR activity response: decreased activity (oranges) or increased activity (greens). Statistical significance of the skill scores is denoted by the light gray diamonds ( $\geq 80$ th percentile) and dark gray squares ( $\geq 90$ th percentile), based on 1000 block bootstrap samples (Methods)

days, or even weeks, to manifest, in agreement with the results of earlier theoretical work. ${ }^{7,37}$ Notably, these patterns emerge despite the high degree of variability (duration, strength, evolution, and so on) within the underlying MJO events.

Despite the revealing patterns in Fig. 2, such an analysis does not assess whether the modulation of AR activity following MJO activity is of use in a predictive sense. Here, we develop an empirical prediction scheme to evaluate the predictive potential of the MJO-AR relationship. In this first version of the scheme, the predictor is the initial state of the MJO, represented simply by the numeric MJO phase on the date of forecast issuance. The predictand is anomalous AR activity at some date in the future (i.e., forecast lead) near a given landfall boundary. While others have evaluated the ability of medium-range weather forecasts to represent individual AR events, ${ }^{38}$ we target periods of AR activity relative to the seasonal cycle and smoothed by a 5-day running mean (Methods). This particular choice of predictand transforms the transient, synoptic-scale nature of individual ARs into a broader representation of the propensity of the large-scale flow pattern to support anomalous AR activity (i.e., increased or decreased activity relative to the seasonal climatology) and is a more suitable target for subseasonal prediction.

Using a leave-one-out cross-validation training and verification approach, we verify the prediction scheme on all DJFM dates for forecast lead times spanning 2-36 days. Forecast leads are defined as the number of days between the initial conditions (i.e., when forecasts are made) and the verification dates (i.e., the dates for which AR activity is forecast). Thus, MJO conditions as early as late October are used as predictors. The Heidke skill score (HSS;
Methods) is used to quantify the value added by this prediction scheme. As constructed, the HSS ranges from -100 (no correct forecasts) to 100 (all forecasts are correct), and HSS values $>0$ indicate conditions when the scheme adds value compared to a climatological forecast.

Figure 3 depicts the skill of the empirical prediction scheme as a function of MJO phase and forecast lead time for the British Columbia and California landfall boundaries. The panels in Fig. 3 are shaded where the HSS is positive, that is, where skill emerges from this empirical prediction scheme (see Supplementary Fig. S6 for a plot of the full range of scores comparable to Fig. 3a, b). The extent of the shading in Fig. 3a, b reveals that the MJO-AR relationship provides useful information within the subseasonal time scale beyond a simple climatological forecast. For context, an HSS value of 33 means that there are twice as many correct forecasts as incorrect forecasts. The color of the shading in Fig. 3 relates to the $A R$ response, with orange shading for decreased AR activity and green shading for increased AR activity. The skillful response patterns in Fig. 3a, b share some similarities with the composite patterns shown in Fig. 2. For example, the band of anomalously high AR activity near British Columbia following MJO phases 1-6 in Fig. 2a supports skillful predictions of increased AR activity following the same phases in Fig. 3a. Additionally, the patterns of skillful predictions suggest that the composites in Fig. 2 are not dominated by just a few outlier events, but rather capture robust shifts in AR activity due to the state of the MJO up to 5 weeks prior.

Inspired by recent work investigating the impacts of the QBO on the MJO, we repeat our predictions but now include the phase of the QBO as an additional predictor. In Fig. 3, panels c-f follow 
a) EQBO, MJO Phase 1, +18 Days

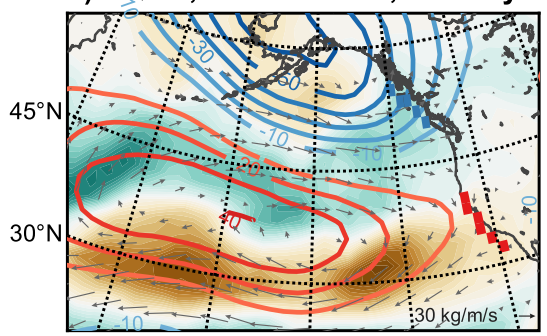

c) EQBO, MJO Phase 5, +12 Days

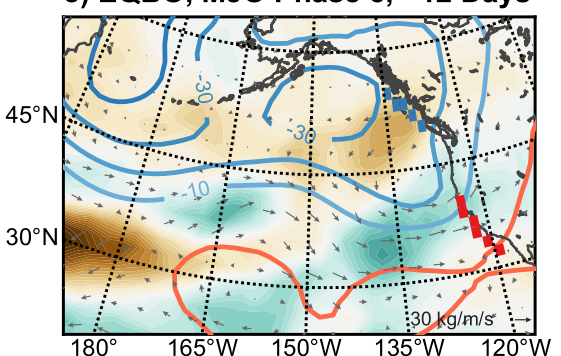

b) WQBO, MJO Phase 1, +18 Days

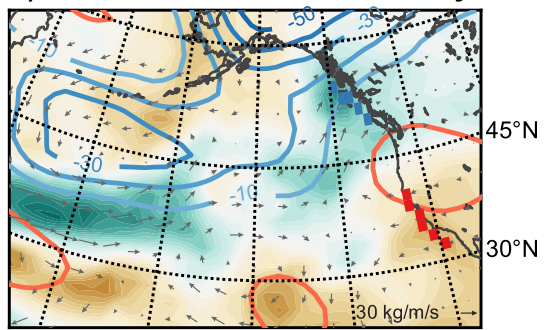

d) WQBO, MJO Phase 5, +12 Days

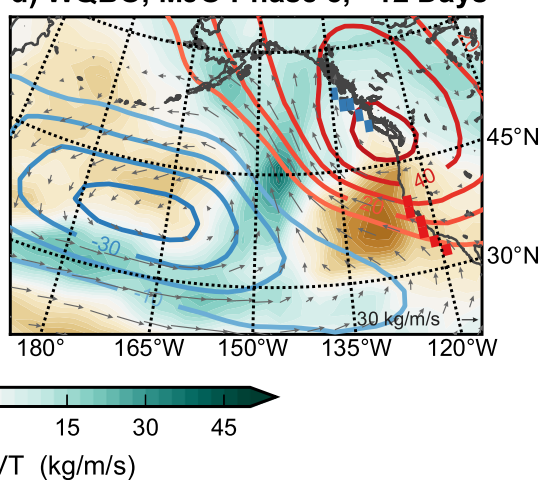

Fig. 4 Composites of anomalous integrated water vapor transport (IVT; shaded and arrows), positive $500 \mathrm{hPa}$ geopotential height anomalies (red contours), and negative $500 \mathrm{hPa}$ geopotential height anomalies (blue contours) for (a) 18 days following DJFM MJO phase 1 dates during EQBO conditions, (b) 18 days following MJO phase 1 dates during WQBO, (c) 12 days following MJO phase 5 dates during EQBO, and (d) 12 days following MJO phase 5 dates during WQBO. The British Columbia (blue) and California (red) landfall boundaries are overlaid

the format of $a$ and $b$, but are parsed according to QBO phase: easterly QBO (EQBO) and westerly QBO (WQBO). As an example, the streak of statistically significant skill for increased AR activity near British Columbia during EQBO conditions and 18-26 days following MJO phase 1 (bottom row of Fig. 3c) indicates that given the initial conditions of EQBO and active MJO phase 1, one should expect an increase in $A R$ activity relative to the seasonal climatology $\sim 3$ weeks following. The skill metric suggests that such a prediction of increased AR activity would be correct $\sim 20$ times out of 30. We also find that when the prediction scheme adds value (HSS $>0$ ), the skill is often higher with the addition of the $\mathrm{QBO}$ as a predictor. While some of the general skill and response patterns from the "QBO independent" panels remain once parsed by QBO phase, it is apparent that the patterns of anomalous AR activity in Fig. 3a, b are generally dominated by different phases of the QBO. For example, the band of increased AR activity near British Columbia 1-3 weeks following MJO phases $1-3$ is most pronounced during EQBO conditions.

To learn more about the dynamics that contribute to the AR response patterns shown in Fig. 3, we examine composites of integrated water vapor transport (IVT) and $500 \mathrm{hPa}$ geopotential height anomalies over the North Pacific. The large-scale anomaly patterns reveal conditions that act to influence AR activity near the landfall boundaries. Perhaps not surprisingly, the more skillful the prediction scheme (i.e., higher and more significant HSS), the more coherent the associated anomaly patterns appear over the North Pacific. For example, conditional composites for 18 days following MJO phase 1 dates during EQBO and WQBO conditions are shown in Fig. 4a, b, respectively. In Fig. 4a, a negative height anomaly centered over mainland Alaska contrasts with a broad positive height anomaly encompassing much of the North Pacific. These anomaly patterns favor anomalously high AR activity near British Columbia and low AR activity near California. The anomaly patterns are less pronounced during WQBO conditions (Fig. 4b), but the associated AR activity impacts are of the same sign regardless of QBO phase. In contrast, $\mathrm{c}$ and d of Fig. 4 show composite conditions for 12 days following MJO phase 5 dates with dissimilar extratropical anomaly patterns when parsed by QBO phase and with the composite anomaly pattern appearing substantially weaker and less coherent in the EQBO phase. In both panels, the composite height and IVT anomaly patterns are conducive for an AR activity tradeoff between the two landfall boundaries. ${ }^{34}$ Overall, the example composites shown in Fig. 4 highlight that the anomalous AR response patterns (e.g., Fig. 3) are linked to the large-scale modulation of the extratropical circulation.

A worthwhile question is how does the level of skill from this empirical prediction scheme compare to the skill available from numerical weather prediction models? To answer this question, we evaluate a suite of 46-day European Centre for Medium-Range Weather Forecasts (ECMWF) retrospective forecasts initialized from 1995 to $2016 .{ }^{2}$ As with the empirical method, we target 5day average anomalous AR activity for each landfall boundary. Figure 5 shows the resulting HSS based on all verification dates in DJFM as a function of forecast lead time for both the British Columbia (blue) and California (red) landfall boundaries. The ECMWF ensemble prediction system shows skill initially; however, the skill decreases to near zero at $\sim 18$ days. Thus, the model's subseasonal skill with this metric is roughly equivalent to a climatological forecast beyond forecast lead times of 18 days. The HSS values plotted in Fig. 5 are not parsed by MJO and QBO phase; however, as shown in the Supplementary Figs. S10 and $\mathrm{S} 11$, the results do not vary remarkably when the initial state of the MJO and the QBO are considered. This brief assessment is not intended to be a critique of this particular model, but rather to provide a rough estimate of the ability of a current generation numerical weather prediction model to predict anomalous $A R$ activity within the subseasonal time scale.

\section{DISCUSSION}

This study illuminates the predictive potential of the relationship between anomalous landfalling AR activity along the west coast of 


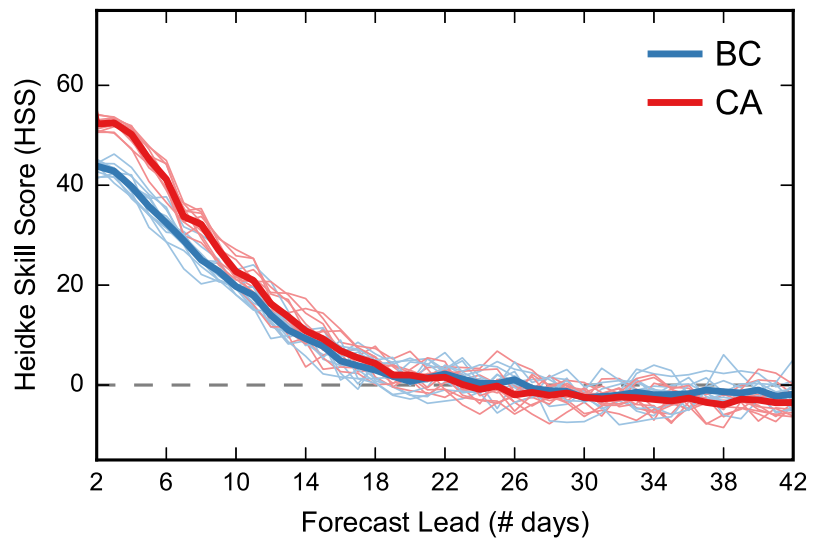

Fig. 5 HSS values based on ECMWF reforecast predictions of anomalous AR activity as a function of forecast lead time ( $x$ axis) for the British Columbia (BC; blue) and California (CA; red) landfall boundaries. Fine lines represent individual ensemble members and the bold lines denote the mean skill of all ensemble members for each region

North America and the state of the tropics up to 5 weeks prior. Earlier works have documented an MJO-AR relationship in terms of the modulation of AR occurrences ${ }^{30-32}$ and their impacts, ${ }^{29}$ but here we demonstrate that the time-lagged modulation of $A R$ activity by the extratropical response to the MJO can be leveraged for skillful subseasonal forecasts. We further show that the MJO-AR relationship is influenced by the $\mathrm{QBO}$. Thus, the variability of the MJO-AR relationship can be better understood and predicted by also considering the state of the stratosphere. Furthermore, key aspects of the skill and AR response patterns are generally robust to the indices and thresholds used to characterize the MJO and the QBO (Supplementary Information).

An empirical prediction scheme using the initial state of the MJO and the QBO as predictors can support skillful subseasonal "forecasts of opportunity." As shown, during certain phase combinations (i.e., MJO phase, QBO phase, and forecast lead) the prediction scheme produces skill at forecast lead times of 2-5 weeks exceeding that of a state-of-the-art numerical weather prediction model, when evaluated using a similarly-constructed metric for above and below normal AR activity. Our scheme could be operationalized in such a manner as to revert to climatology if no additional skill can be expected, thus affording continuous application to complement available numerical weather prediction guidance. Furthermore, the method could be married with predictions of the MJO itself, predictions that now show skill out 3-4 weeks in some dynamic models and situations. ${ }^{39-41}$

As ARs can trigger wide-ranging impacts, even modest gains in the subseasonal prediction of these impactful features may benefit numerous sectors of society. Also significant is the result that the MJO-AR relationship is responsible for not only periods of increased landfalling AR activity, but also periods of decreased activity. Given the potential consequences of a lack of AR activity, inactive periods may be just as viable and valuable a predictive target as abnormally active periods. Whatever the response, this study elucidates key relationships that contribute to the subseasonal variability of these extreme events and support skillful predictions thereof.

\section{METHODS}

\section{Atmospheric river detection}

ARs are identified using an updated version of an objective detection algorithm (as documented in ref. ${ }^{32}$ ). The algorithm uses gridded fields of positive anomalous vertically integrated water vapor transport (IVT), together with a series of intensity and geometric tests (e.g., mean intensity, total area, length, length-to-width ratio), to identify features that are of the appropriate spatial scale and are sufficiently plumelike in nature. This detection algorithm employs an occurrence-based approach (i.e., an AR occurrence is recorded for each period during which the criteria are satisfied), wherein each time step is scrutinized independently. As a result, the calculations regarding AR "hits" described in this study are based on the number of days during which AR-like conditions exist over a given landfall boundary. The updated detection algorithm used in this study does not contain the "multiple peak" logic that scrutinizes connected features within fields of anomalous IVT. We find that the mid- and highlatitude results are generally insensitive to the removal of this logic test. The majority of the results presented in this work are based on this detection algorithm applied to IVT calculated via the mass-weighted vertical integration of component winds and specific humidity from $1000-250 \mathrm{hPa}$ from MERRA- $2 .^{35}$ Daily means are calculated and the data set is regridded to a $1.5^{\circ} \times 1.5^{\circ}$ latitude-longitude grid before calculating IVT. With this data set, a static anomalous IVT magnitude threshold of $\sim 173 \mathrm{~kg} \mathrm{~m}^{-1} \mathrm{~s}^{-1}$ is used to isolate features of interest. This value represents the 94th percentile of the all-season distribution of daily IVT anomaly values over the North Pacific Ocean. For the model skill comparison, this AR detection scheme is also applied to gridded IVT anomalies calculated from a set of retrospective forecasts from the ECMWF reforecast ensemble prediction system.

\section{Atmospheric river activity}

To construct time series of anomalous AR activity along the landfall boundaries, we first create a continuous time series of boolean AR "hits" for each boundary by recording a hit whenever the spatial extent of any AR feature overlaps at least one grid point of a given landfall boundary. Second, we remove the seasonal cycle of AR activity by subtracting the mean and first two harmonics calculated via fast Fourier transform applied to the calendar-day means of each AR time series. Third, we apply a 5-day running mean to each anomaly time series. Based on the premise that subseasonal predictions are founded on the presence and modulation of large-scale circulation anomalies, the running mean transitions the time series from representing only individual transient hits to capturing the larger-scale propensity of the anomalous flow pattern to influence the landfalling activity. The resulting time series are used to create the conditional composites for Fig. 2 and to train and verify the prediction scheme described throughout this work.

\section{Predictors}

Two potential sources of subseasonal predictability are used as initial conditions for the prediction scheme: the MJO and the QBO. We characterize the MJO according to the strength and location of the enhanced near-equatorial convection and the associated anomalous circulation, as determined by the components of the RMM index. ${ }^{36}$ This MJO index is a combination of two component indices, RMM1 and RMM2, representing the two leading principal components from a multivariate (equatorially averaged tropical outgoing longwave radiation and 200- and $850-\mathrm{hPa}$ zonal winds) empirical orthogonal function analysis. When combined and considered in terms of their two-dimensional phase space, these component indices provide daily phase (1-8) and amplitude values (see ref. ${ }^{36}$ ). We consider the MJO as active when the amplitude meets or exceeds a value of one and also apply the basic logic test that the index must remain in that phase (e.g., location of active MJO signal) for at least two, but less than 20, days. See the Supplementary Information for alternative characterizations of the MJO (e.g., different index or more stringent phase event criteria). The $\mathrm{QBO}$ is characterized by the standardized monthly $50-\mathrm{hPa}$ zonal wind index provided by the National Oceanic and Atmospheric Administration (NOAA) National Weather Service (NWS) Climate Prediction Center (CPC). We apply this index as a continuous time series, such that all months within the period of record are categorized as either EQBO (monthly mean standardized anomaly $<0$ ) or WQBO $(>0)$. We show the impact of introducing a more restrictive anomaly threshold, which has the possible effect of bolstering the prediction scheme, but also reducing the number of conditional samples, in the Supplementary Fig. S13. The QBO is not considered alone based on the presumption that the influence of the QBO on anomalous AR activity will primarily manifest via the modulation of the MJO's convection and its ability to elicit an extratropical response. Hence, the predictors investigated in this study are simply the daily MJO phase (1-8) and the monthly QBO phase (EQBO or WQBO). 


\section{Empirical prediction}

We generate a two-class prediction scheme from the DJFM AR anomaly time series for each region; that is, we assess the probability of being above and the probability of being below an "equal chances" 50th percentile of the time series, given the initial state of the MJO and the QBO. As constructed, the probability of being above (increased AR activity) and below (decreased AR activity) are equal when all verification dates in DJFM are considered. However, the probability distribution may shift as a function of MJO phase, QBO phase, and forecast lead. For the example shown in Supplementary Fig. S5, the distribution of 5-day average anomalous AR activity near British Columbia is shifted toward higher values 18 days following MJO phase 1 dates during EQBO conditions, relative to the mean DJFM distribution. As a result, given the initial conditions of MJO phase 1 and EQBO, the empirical scheme will predict increased AR activity for the British Columbia landfall boundary around 18 days following these initial conditions. In evaluating the two-class scheme, a prediction is considered correct when the observed response, in terms of above or below the 50th percentile threshold, from the 5-day running mean of the independent verification time series matches the predicted response; the prediction is considered incorrect otherwise. As illustrated by this example, the predictors are not explicitly weighted as they may be in a scheme based on some form of regression; in contrast, the predictors (MJO phase and QBO phase) are simply used to parse the training data in order to assess the conditional shift in the likelihood of increased or decreased AR activity relative to seasonal climatology. Though the results presented herein are based on the use of a single DJFM 50th percentile threshold, we find that the overarching conclusions (timelagged response, patterns of increased/decreased AR activity, and so on) remain even if the threshold is allowed to vary by day-of-season. We use a leave-one-out cross-validation approach to conditionally construct and evaluate this prediction scheme. ${ }^{42}$ Specifically, the verification statistics for a given season are based on distributions constructed from historical AR activity parsed by phase of the MJO and the QBO for all DJFM seasons excluding the one "left out" verification season, ensuring independence of the verification subset. As a given season is left out, we use the training data to generate forecasts for all 121 days within the left out season and for all possible forecast leads. In so doing, we perform this leave-one-out procedure 36 times, each time leaving out just one DJFM season from the available MERRA-2 record. Because the training periods differ during the leave-one-out process, the 50th percentile threshold is recalculated each time; however, the threshold value is nearly unchanged throughout the cross-validation. The output of the cross-validation procedure is the number of correct and incorrect predictions parsed by initial conditions and forecast lead times.

\section{Skill assessment}

The skill of the prediction scheme is evaluated using the HSS, a measure of the proportion of correct forecasts. ${ }^{13,42}$ The HSS is calculated as:

$H S S=\frac{(H-E)}{(T-E)} \times 100$,

where $H$ is the number of correct forecasts, $T$ is the total number of forecasts evaluated, and $E$ is the number of correct forecasts expected by chance (T/2 in this two-class scenario). With the multiplication by 100 , the two-class HSS ranges from -100 to 100 . A set of perfect forecasts garners a HSS of 100 , forecasts equivalent to the reference forecast (i.e., climatology) score 0 , and forecasts less skillful than the reference forecast receive negative scores. The HSS values may be interpreted in terms of value added relative to a climatological reference forecast. For example, a HSS of 33 indicates twice as many correct forecasts as incorrect forecasts and a skill score of 50 indicates three times as many correct as incorrect forecasts; whereas, the reference forecast with a skill score of 0 indicates an equal number of correct and incorrect forecasts.

\section{Significance of skill}

A block bootstrapping approach is used to assess the statistical significance of the HSS values. For every conditional combination (i.e., MJO phase, QBO phase, and forecast lead), we generate a distribution of 1000 skill score values by randomly reassigning the calendar year and shifting the day-of-year indices of the "blocks" of the occurrences of the conditional data. We then perform the verification calculations on the random data in order to construct a distribution of resampled HSS values against which the actual conditional HSS may be compared. In doing so, each block bootstrap sample retains the sample size and potential autocorrelation associated with the conditional data.

\section{Atmospheric river response assessment}

For Fig. 3 and the associated discussion, we aim to not only communicate the skill within the prediction scheme, but also characterize the conditional $A R$ response. To achieve this, we evaluate the shift in the probability of above and below normal AR activity for each conditional combination throughout the leave-one-out training and verification process. For example, if a given MJO phase, QBO phase, and forecast lead combination consistently produces a probability of above normal AR activity greater than the probability of below normal activity, we record the condition as resulting in above normal, or increased, AR activity and shade the combination green in Fig. 3.

\section{Model skill comparison}

In order to provide a numerical weather prediction skill benchmark, we calculate HSS values for a set of 46-day ECMWF retrospective forecasts from 1995 to 2016. The ECMWF reforecast ensemble prediction system data set consists of 11 members ( 1 control and 10 perturbed) that are created "on-the-fly." That is to say that the database is comprised of output from different versions of the ECMWF model, as reforecasts are produced progressively as the the operational model is updated. ${ }^{2}$ We obtain instantaneous 0000 UTC variables on a $1.5^{\circ} \times 1.5^{\circ}$ latitude-longitude grid, from which we calculate IVT and identify AR-like features. We use the first 7 days from every available control run reforecast to calculate calendar-day means from which we calculate the seasonal cycle via fast Fourier transform. Time series of anomalous AR activity are created for each ensemble member's reforecasts by removing the control run's seasonal cycle and applying a 5-day running mean. The 50th percentile threshold used to evaluate AR activity is based on anomalies from the control run, subset for the boreal winter. Each member is evaluated separately and for all verification dates within DJFM. Following this approach, 1919 reforecasts are used.

\section{Data availability}

MERRA-2 data were obtained from the NASA Goddard Earth Sciences Data and Information Services Center (https://disc.gsfc.nasa.gov/). ECMWF reforecast ensemble system output was acquired from the World Weather Research Programme/World Climate Research Programme Subseasonal-toSeasonal Prediction Project database ${ }^{2}$ (http://apps.ecmwf.int/datasets/ data/s2s/). The QBO index was provided by the NOAA NWS CPC (http:// www.cpc.ncep.noaa.gov/data/indices/qbo.u50.index). MJO indices were obtained from the Australian Bureau of Meteorology (http://www.bom. gov.au/climate/mjo/) and NOAA Earth System Research Laboratory (https://www.esrl.noaa.gov/psd/mjo/mjoindex/).

\section{ACKNOWLEDGEMENTS}

Financial support for this study was provided, in part, by the National Science Foundation Climate and Large-Scale Dynamics Program under grant AGS-1441916, the NOAA Modeling, Analysis, Predictions, and Projections Program S2S Prediction Task Force under grant NA16OAR4310064, and the NOAA NWS Office of Science and Technology grant NA16NWS4680022.

\section{AUTHOR CONTRIBUTIONS}

B.D.M. led this study with contributions from all authors regarding the research methods and the interpretation of the results. C.F.B. obtained and processed the ECMWF reforecast output. B.D.M. drafted the manuscript and all authors contributed to preparing the final version for publication.

\section{ADDITIONAL INFORMATION}

Supplementary information accompanies the paper on the npj Climate and Atmospheric Science website (https://doi.org/10.1038/s41612-017-0008-2).

Competing interests: The authors declare that they have no competing financial interests.

Publisher's note: Springer Nature remains neutral with regard to jurisdictional claims in published maps and institutional affiliations. 
Change history: The original version of this Article had an incorrect Article number of 7 and an incorrect Publication year of 2017. These errors have now been corrected in the PDF and HTML versions of the Article.

\section{REFERENCES}

1. Robertson, A. W., Kuma, A., Peña, M. \& Vitart, F. Improving and promoting subseasonal to seasonal prediction. Bull. Am. Meteor. Soc. 96, ES49-ES53 (2015).

2. Vitart, F. et al. The subseasonal to seasonal (S2S) prediction project database. Bull. Am. Meteor. Soc. 98, 163-173 (2017).

3. White, C. J. et al. Potential applications of subseasonal-to-seasonal (S2S) predictions. Meteor. Appl. 24, 315-325 (2017).

4. Black, J. et al. The predictors and forecast skill of Northern Hemisphere teleconnection patterns for lead times of 3-4 weeks. Mon. Wea. Rev. 145, 2855-2877 (2017).

5. Hoskins, B. J. \& Karoly, D. J. The steady linear response of a spherical atmosphere to thermal and orographic forcing. J. Atmos. Sci. 38, 1179-1196 (1981).

6. Sardeshmukh, P. D. \& Hoskins, B. J. The generation of global rotational flow by steady idealized tropical divergence. J. Atmos. Sci. 45, 1228-1251 (1988).

7. Matthews, A. J. Atmospheric response to observed intraseasonal tropical sea surface temperature anomalies. Geophys. Res. Lett. 31, L14107 (2004).

8. Hoskins, B. J. The potential for skill across the range of the seamless weatherclimate prediction problem: a stimulus for our science. Quart. J. Roy. Meteor. Soc. 139, 573-584 (2013).

9. Zhang, C. Madden-Julian oscillation: bridging weather and climate. Bull. Am. Meteor. Soc. 94, 1849-1870 (2013).

10. Zhang, C. Madden-Julian oscillation. Rev. Geophys. 43, RG2003 (2005).

11. Gottschalck, J. et al. A framework for assessing operational Madden-Julian oscillation forecasts: a CLIVAR MJO Working Group project. Bull. Am. Meteor. Soc 91, 1247-1258 (2010).

12. Waliser, D. E. in Chapter 12, Intraseasonal Variability of the Atmosphere-Ocean Climate System 2nd edn (eds Lau, W. K. M. \& Waliser, D. E.) Predictability and forecasting (Springer, Heidelberg, 2011).

13. Johnson, N. C., Collins, D. C., Feldstein, S. B., L'Heureux, M. L. \& Riddle, E. E. Skillful wintertime North American temperature forecasts out to 4 weeks based on the state of ENSO and the MJO. Wea. Forecast. 29, 23-38 (2014).

14. DelSole, T., Trenary, L., Tippett, M. K. \& Pegion, K. Predictability of week-3-4 average temperature and precipitation over the contiguous United States. J. Clim. 30, 3499-3512 (2017)

15. Scaife, A. A. et al. Predictability of the quasi-biennial oscillation and its northern winter teleconnection on seasonal to decadal timescales. Geophys. Res. Lett. 41, 1752-1758 (2014).

16. Baldwin, M. P. et al. The quasi-biennial oscillation. Rev. Geophys. 39, 179-229 (2001).

17. Yoo, C. \& Son, S.-W. Modulation of the boreal wintertime Madden-Julian oscillation by the stratospheric quasi-biennial oscillation. Geophys. Res. Lett. 43, 1392-1398 (2016).

18. Marshall, A. G., Hendon, H. H., Son, S.-W. \& Lin, Y. Impact of the quasi-biennial oscillation on predictability of the Madden-Julian oscillation. Clim. Dyn. 49, 1365 (2017).

19. Son, S., Lim, Y., Yoo, C., Hendon, H. \& Kim, J. Stratospheric control of MaddenJulian oscillation. J. Clim. 30, 1909-1922 (2017).

20. Liu, C. et al. Northern Hemisphere mid-winter vortex-displacement and vortex-split stratospheric sudden warmings: influence of the Madden-Julian oscillation and quasi-biennial oscillation. J. Geophys. Res. Atmos. 119, 12599-12620 (2014).

21. Nishimoto, E. \& Yoden, S. Influence of the stratospheric quasi-biennial oscillation on the Madden-Julian oscillation during Austral summer. J. Atmos. Sci. 74, 1105-1125 (2017).

22. Ralph, F. M. et al. Flooding on California's Russian River: the role of atmospheric rivers. Geophys. Res. Lett. 33, L13801 (2006).

23. Smith, B. L., Yuter, S. E., Neiman, P. J. \& Kingsmill, D. E. Water vapor fluxes and orographic precipitation over Northern California associated with a landfalling atmospheric river. Mon. Wea. Rev. 138, 74-100 (2010).
24. Neiman, P. J., Schick, L. J., Ralph, F. M., Hughes, M. \& Wick, G. A. Flooding in western Washington: the connection to atmospheric rivers. J. Hydrometeor. 12, 1337-1358 (2011).

25. Ralph, F. M. \& Dettinger, M. D. Storms, floods, and the science of atmospheric rivers. Eos, Trans. Am. Geophys. Union 92, 265-272 (2011).

26. Dettinger, M. D., Ralph, F. M., Das, T., Neiman, P. J. \& Cayan, D. R. Atmospheric rivers, floods, and the water resources of California. Water 3, 445-478 (2011).

27. Dettinger, M. D. Atmospheric rivers as drought busters on the U.S. West Coast. J. Hydrometeor. 14, 1721-1732 (2013).

28. Ralph, F. M., Neiman, P. J., Kiladis, G. N., Weickmann, K. \& Reynolds, D. W. A multiscale observational case study of a Pacific atmospheric river exhibiting tropical/extratropical connections and a mesoscale frontal wave. Mon. Wea. Rev. 139, 1169-1189 (2011).

29. Guan, B., Waliser, D. E., Molotch, N. P., Fetzer, E. J. \& Neiman, P. J. Does the Madden-Julian oscillation influence wintertime atmospheric rivers and snowpack in the Sierra Nevada? Mon. Wea. Rev. 140, 325-342 (2012).

30. Payne, A. E. \& Magnusdottir, G. Dynamics of landfalling atmospheric rivers over the North Pacific in 30 years of MERRA reanalysis. J. Clim. 27, 7133-7150 (2014).

31. Guan, B. \& Waliser, D. E. Detection of atmospheric rivers: evaluation and application of an algorithm for global studies. J. Geophys. Res. Atmos. 120, 12514-12535 (2015).

32. Mundhenk, B. D., Barnes, E. A. \& Maloney, E. D. All-season climatology and variability of atmospheric river frequencies over the North Pacific. J. Clim. 29, 4885-4903 (2016).

33. Neiman, P. J., Ralph, F. M., Wick, G. A., Lundquist, J. D. \& Dettinger, M. D. Meteorological characteristics and overland precipitation impacts of atmospheric rivers affecting the west coast of North America based on eight years of SSM/I satellite observations. J. Hydrometeor. 9, 22-47 (2008).

34. Mundhenk, B. D., Barnes, E. A., Maloney, E. D. \& Nardi, K. M. Modulation of atmospheric rivers near Alaska and the U.S. West Coast by northeast Pacific height anomalies. J. Geophys. Res. Atmos. 121, 12751-12765 (2016).

35. GMAO. MERRA-2 inst6_3d_ana_Np: 3d, 6-hourly, instantaneous, pressure-level, analysis, analyzed meteorological fields V5.12.4, 2015.

36. Wheeler, M. C. \& Hendon, H. H. An all-season real-time multivariate MJO index: development of an index for monitoring and prediction. Mon. Wea. Rev. 132, 1917-1932 (2004).

37. Jin, F. \& Hoskins, B. J. The direct response to tropical heating in a baroclinic atmosphere. J. Atmos. Sci. 52, 307-319 (1995).

38. Wick, G. A., Neiman, P. J., Ralph, F. M. \& Hamill, T. M. Evaluation of forecasts of the water vapor signature of atmospheric rivers in operational numerical weather prediction models. Wea. Forecast. 28, 1337-1352 (2013).

39. Vitart, F. \& Molteni, F. Simulation of the Madden-Julian oscillation and its teleconnections in the ECMWF forecast system. Quart. J. Roy. Meteor. Soc. 136 842-855 (2010).

40. Wang, W., Hung, M.-P., Weaver, S., Kumar, A. \& Fu, X. MJO prediction in the NCEP climate forecast system version 2. Clim. Dyn. 42, 2509-2520 (2014).

41. Kim, H.-M. et al. MJO propagation across the Maritime Continent in the ECMWF ensemble prediction system. J. Clim. 29, 3973-3988 (2016).

42. van den Dool, H. Empirical Methods in Short-Term Climate Prediction (Oxford University Press, New York, 2007).

Open Access This article is licensed under a Creative Common cc) Attribution 4.0 International License, which permits use, sharing, adaptation, distribution and reproduction in any medium or format, as long as you give appropriate credit to the original author(s) and the source, provide a link to the Creative Commons license, and indicate if changes were made. The images or other third party material in this article are included in the article's Creative Commons license, unless indicated otherwise in a credit line to the material. If material is not included in the article's Creative Commons license and your intended use is not permitted by statutory regulation or exceeds the permitted use, you will need to obtain permission directly from the copyright holder. To view a copy of this license, visit http://creativecommons. org/licenses/by/4.0/.

(c) The Author(s) 2018 